https://helda.helsinki.fi

\title{
Emissions trading, non-compliance and bankable permits
}

\section{Lappi, Pauli}

2017-12

Lappi , P 2017 , ' Emissions trading, non-compliance and bankable permits ' , International

Tax and Public Finance, vol. 24 , no. 6 , pp. 1081-1099 . https://doi.org/10.1007/s10797-017-9439-2

http://hdl.handle.net/10138/298116

https://doi.org/10.1007/s10797-017-9439-2

acceptedVersion

Downloaded from Helda, University of Helsinki institutional repository.

This is an electronic reprint of the original article.

This reprint may differ from the original in pagination and typographic detail.

Please cite the original version. 


\title{
Emissions trading, non-compliance and bankable permits*
}

\author{
Pauli Lappi ${ }^{\dagger}$
}

*Acknowledgements: The author thanks Markku Ollikainen, Essi Eerola, Kimmo Ollikka, Chiara Lombardini, Lassi Ahlvik, Marko Lindroos and the participants of the EAERE 2013 conference in Toulouse for their helpful comments. Any remaining errors are my own. Financial support from the OP-Pohjola Group Research Foundation is gratefully acknowledged.

${ }^{\dagger}$ Department of Economics and Management, Latokartanonkaari 7, PO Box 00014 University of Helsinki; e-mail pauli.lappi@helsinki.fi. 


\begin{abstract}
We study non-compliance in an emissions trading system in which firms may bank and borrow permits. We find a condition involving subjective auditing probability that characterizes compliance and allows us to analyze the time paths of actual emissions, reported emissions and violations. We find two interesting time instants. At the first time instant, reported emissions begin to be lower than the actual emissions, and at the second time instant, the reported emissions become zero and the actual emissions become constant. The results indicate, among other things, that a given penalty scheme may fail to induce compliance over the whole planning interval, even though it achieves compliance over the initial stage.

Keywords: Banking, compliance, emissions trading, enforcement, monitoring.

JEL codes: Q50, Q58.
\end{abstract}




\section{Introduction}

Intertemporal flexibility through the banking and borrowing of permits is an advantage that emissions trading system has over other economic instruments. Banking and borrowing of permits offers firms the opportunity to abate emissions either earlier or later within the emissions cap while reducing total compliance costs over the entire compliance period. Understanding the effects of banking and borrowing of permits is important, since many trading systems in practice contain at least the possibility to bank permits from one period to another and some systems also allow borrowing. For example, banking and borrowing are allowed in the Quebéc Cap and Trade System, in the European Union Emissions Trading Scheme (EU ETS) (Chevallier 2012), in the American Power Act (APA) (Leard 2013) and in the Regional Greenhouse Gas Initiative (RGGI) (Holland and Moore 2013). Borrowing in these aforementioned programs is often restricted and these restrictions may come in many forms. In some programs, such as the EU ETS, it is possible only to borrow permits from the following year's allocation. In RGGI, it is possible to borrow permits freely during the three year compliance period. (Holland and Moore 2013.) In the Quebéc Cap and Trade System, it is possible to bank and borrow permits freely during the three year compliance period (Quebéc Government). ${ }^{1}$

The properties of banking have been studied in the literature as they are an important

\footnotetext{
${ }^{1}$ In this system every emitter must have on 1 November after the end of the compliance period at least as many allowances as their verified emissions (Quebéc Government, Title II, Chapter III 21.)
} 
component of emissions trading programs. Cronshaw and Kruse (1996), Rubin (1996) and Kling and Rubin (1997) have studied the theoretical properties and effects of banking and borrowing. Rubin (1996) shows that firms' choices result in a least-cost solution, that is, they minimize the joint-costs of abatement. Rubin also studies the time paths of permit price and emissions when both banking and borrowing are allowed, and finds that the Hotelling's rule of exhaustible resources holds for the permit price, and that the path of emissions over time is therefore decreasing. Although the total abatement costs are minimized, the total social damages from emissions may be increased, if intertemporal trading is allowed, as Kling and Rubin (1997) have argued.

Like other environmental policy instruments, emissions trading with banking and borrowing must be enforced to prevent or to reduce illegal emissions. ${ }^{2}$ The literature on the monitoring and enforcement of emissions trading, and of environmental regulation in general, is vast. Malik (1990) was the first to study emissions trading and non-compliance, and found that emissions trading may not be cost-efficient under non-compliance. Since Malik's work the literature has studied different aspects of emissions trading and noncompliance including market power (van Egteren and Weber 1996 and Malik 2002), properties of the enforcement scheme (Stranlund and Dhanda 1999) and uncertainty (Montero 2002 and Stranlund and Moffitt 2014). It is surprising that at least to our knowledge only

\footnotetext{
${ }^{2}$ In the EU ETS the monitoring, enforcement and self-reporting are carried out during the annual compliance cycle. This cycle includes the accredited inspections and compliance checks by the competent authority.
} 
two papers, Stranlund et al. (2005) and Innes (2003), study the enforcement of emissions trading under the possibility that firms can bank or borrow permits. ${ }^{3}$ Stranlund et al. (2005) use a discrete-time model to analyze the design of monitoring and enforcement that results in full compliance. They find that full compliance can be achieved by imposing constant penalties for violations that depend on the permit price. In their model, the auditing probability function is an objective probability function in the sense that the regulator knows the auditing probability the firms use in their optimization. ${ }^{4}$

The alternative to objective probability is to assume that the probability is subjective. ${ }^{5}$ This means that the firm makes its compliance decision based on the beliefs the firm has about the likelihood that the regulator will audit the firm, or as Sandmo (2002) writes on page 91: "the properties of the probability functions reflect the beliefs of the firms with respect to the nature of public environmental policies and these beliefs are essentially subjective". In contrast to objective auditing probability, the subjective auditing probability implies that the regulator does not know the probability the firms use in their optimization.

\footnotetext{
${ }^{3}$ Innes (2003) has analyzed intertemporal permit markets under stochastic emissions. Innes shows that by allowing intertemporal trading the regulator can decrease the administrative costs related to sanctioning violations. The static literature related to monitoring and enforcement includes also Malik (1992), Stranlund et al. (2009), Stranlund (2007) and Arguedas et al. (2010). See footnote 5 for additional studies in the static literature.

${ }^{4}$ This probability could simply be the number of audited firms divided by the total number of firms.

${ }^{5}$ Both of these assumptions are used in the literature that consists of static models: objective probability is used in, for example, Malik (1992), Stranlund and Dhanda (1999), Montero (2002), Macho-Stadler and Pérez-Castillo (2006), Stranlund (2007), Stranlund, Chávez, Villena (2009) and Stranlund and Moffitt (2014). Subjective probability is used in, for example, Malik (1990), van Egteren and Weber (1996), Malik (2002), Hatcher (2005), Hatcher (2012) and Sandmo (2002).
} 
The difference between these assumptions is significant. When making its compliance decision, the firm compares the marginal expected cost of non-compliance with the marginal benefit of non-compliance (the permit price): if the marginal expected cost of non-compliance is less than the permit price, the firm non-complies with the regulation by reporting less than the actual emission level. The marginal expected cost of noncompliance involves the auditing probability function and the penalty function, thus the modeling choice regarding the probability function becomes significant. If the firm uses the objective auditing probability, then the penalty function can be conditioned on the going permit price in such a way that compliance is achieved. However, with the subjective auditing probability, the same penalty function may not lead to compliance, if the firm thinks that the probability of auditing is low enough. Another reason for using a subjective probability function is that it is also a more general assumption. The objective probability function is a special case of the subjective probability function, since the firm's view on the auditing process could agree with the true one. ${ }^{6}$

We investigate non-compliance under the constraint that firms are allowed to bank and borrow permits. To this end, we assume that the enforcement policy is weak in the sense

\footnotetext{
${ }^{6}$ The formation of the subjective auditing probability and the relevance of the process regarding environmental policy is outside the scope of this paper and at least to our knowledge remains an open issue. Nevertheless, analyzing some kind of learning-process may be useful in tackling this issue using a different model. Okat (2015), for example, argues that in a repeated interaction the firm learns about the loop-holes of the regulator's auditing technology in order to become more efficient at non-compliance, and as a result it may benefit the auditor to randomize the choice of auditing technology. In this light it is fair to assume that the auditing probability is subjective from the view point of the firm.
} 
that the firm may begin to non-comply at some instant of time. Weak enforcement policy is a result of failed sanctioning policy: The marginal expected cost of non-compliance is not always high enough to guarantee compliance. This possibility may be increased when the probability of auditing is subjective. We have two main questions: How can we characterize the compliance decision of a firm? How does non-compliance affect the paths of emissions, reported emissions and violations? ${ }^{7}$ A similar condition to that which prevails in static models characterizes compliance as follows: if the marginal expected penalty at a zero-level of violation is greater than or equal to the going permit price, the firm is compliant.

This condition is important because it allows us to analyze the consequences of noncompliance on the time paths of emissions, reported emissions and violations, which are unexplored aspects in the enforcement and monitoring literature including Stranlund et al. (2005). We show that a firm that begins to non-comply at some point in time also continues to do so in the future. In fact, the level of non-compliance increases over time, since we show that actual emissions decrease at a lower rate than the reported emissions. An intuitive reason for increasing non-compliance is that along the optimal path the firm equates the marginal benefit of non-compliance (the permit price) with the marginal expected cost, and since the price increases over time, it is optimal for the firm to also

\footnotetext{
${ }^{7}$ By violations we mean the difference between the actual annual emissions and the mandatory annual emissions report.
} 
increase non-compliance to retain the marginal rule.

Furthermore, we show that if a firm is compliant initially, two special instants of time exist for sufficiently large planning interval. In the first instant of time the firm starts to non-comply, and in the second non-compliance becomes maximal in the sense that the reported emissions are thereafter zero and the actual emissions are constant. These results have policy implications, which we discuss at the end of this paper.

The paper continues into section 2, where the set-up of the model is developed together with the necessary conditions for optimum and their economic interpretation. In section 3, we study the conditions that imply full compliance in a dynamic framework. In section 4, we study the time paths of the relevant variables. The last section concludes and offers some relevant policy implications.

\section{Non-compliance in a dynamic model}

\section{$2.1 \quad$ Set-up}

The firms are indexed with $i=1, \ldots, n$. The planning interval is finite $[0, T]$ with a flow of permits $e_{i}^{0}(t)$ to the bank account. During the planning interval, the firm may bank or borrow permits from this account. We use $x_{i}(t)$ to denote the amount of permits purchased or sold at time $t$ (a positive $x_{i}(t)$ denotes a permit purchase, and a negative $x_{i}(t)$, a permit sale) and $e_{i}(t)$ to denote emissions at time $t$. The number of permits in the permit bank is denoted with $B_{i}(t)$. Firm's cost depends on emissions and the abatement 
cost function $C_{i}$ satisfies $C_{i}^{\prime}<0$ and $C_{i}^{\prime \prime}>0$. The revenue from selling or the cost of buying permits at time $t$ is $p(t) x_{i}(t)$, where $p(t)$ is the exogenous permit price at time $t$. We assume that in every period in the planning interval $[0, T]$, the firms must report their emissions, denoted by $\hat{e}(t)$, to the regulator. Since we allow for non-compliance, firm $i$ may report false emission level $\hat{e}_{i}(t)<e_{i}(t)$, implying that the change in the amount of permits in the bank account is described by the equation

$$
\dot{B}_{i}(t)=e_{i}^{0}(t)+x_{i}(t)-\hat{e}_{i}(t)
$$

At terminal time $T$, the amount of permits in the bank account is assumed to be zero (that is, $B_{i}(T)=0$ ). To justify this, we assume that at time $T$, negative amounts of permits in the bank are sanctioned with certainty with a penalty that is strictly greater than the going permit price $p(T)$ and possibly increasing in the size of the permit violation. Then negative amounts of permits in the bank cannot be optimal because the firm could benefit from buying permits from the market. ${ }^{8}$ Moreover, positive amounts of permits in the bank are non-optimal because in this case, the firm could benefit from selling excess permits. Regarding other control variables we also assume that $e_{i}(t) \geq 0$ and $\hat{e}_{i}(t) \geq 0$. Violation $v_{i}(t)$ is equal to $e_{i}(t)-\hat{e}_{i}(t)$. We assume that the firms never find it profitable to report that $\hat{e}_{i}(t)>e_{i}(t) \cdot{ }^{9}$

\footnotetext{
${ }^{8}$ This assumption is in line with the EU ETS rules: in the EU ETS firms are sanctioned at least with a penalty of 100 euros $/ \mathrm{tCO}_{2}$, if they fail to surrender sufficient allowances in time (European Commission, page 16). Note that the current price of allowances is about 10 euros $/ \mathrm{tCO}_{2}$. Negative permit bank in period $T$ means that the firm fails to surrender permits, and must pay a penalty presumably greater than the permit price.

${ }^{9}$ Inequality $\hat{e}_{i}(t)>e_{i}(t)$ would imply less valuable permits in the permit bank compared to the case
} 
The regulator conducts periodic audits. If the firm is audited at some point, and is found to have emitted more than the reported emissions, the firm must pay a penalty depending on the violation $v_{i}(t) .{ }^{10}$ We assume that the penalty function $h$ has the following properties: $h(0)=0, h^{\prime}>0$ and $h^{\prime \prime}>0$. The probability of auditing is $\sigma_{i}\left(v_{i}(t)\right)$, with $\sigma_{i}(0) \geq 0, \sigma_{i}^{\prime} \geq 0$ and $\sigma_{i}^{\prime \prime} \geq 0$. We define $S_{i}\left(v_{i}(t)\right):=\sigma_{i}\left(v_{i}(t)\right) h\left(v_{i}(t)\right)$ as the expected penalty, where $S_{i}$ is strictly increasing and strictly convex. The discounted expected penalty is $e^{-\rho t} S_{i}\left(v_{i}(t)\right)$, where $\rho$ is the discount rate and $e^{-\rho t}$ is the discount factor.

\subsection{A model of banking and borrowing}

The problem for firm $i$ is to

$$
\begin{aligned}
& \max _{\left\{e_{i}(t), \hat{e}_{i}(t), x_{i}(t)\right\}} \int_{0}^{T} e^{-\rho t}\left[-C_{i}\left(e_{i}(t)\right)-p(t) x_{i}(t)-S_{i}\left(v_{i}(t)\right)\right] \mathrm{d} t \\
& \text { s.t } \quad \dot{B}_{i}(t)=e_{i}^{0}(t)+x_{i}(t)-\hat{e}_{i}(t), \quad B_{i}(0)=B_{i}(T)=0, \\
& e_{i}(t)-\hat{e}_{i}(t) \geq 0, \quad e_{i}(t) \geq 0, \quad \hat{e}_{i}(t) \geq 0 .
\end{aligned}
$$

The first inequality constraint reflects the fact that the firm may wish to be noncompliant at some time instant. The generalized Hamiltonian $L$ is

$$
L=H+\mu(t)[e(t)-\hat{e}(t)]+\gamma_{1}(t) e(t)+\gamma_{2}(t) \hat{e}(t),
$$

with equality. This report is not profitable for the firm, because there is no corresponding (or greater) gain to the value of lost permits.

${ }^{10}$ If the firm must surrender the missing permits to the regulator, it may buy them from the market. This transaction has no net effect on the bank account of permits since the firm in turn surrenders the permits to the regulator. 
where

$$
H=e^{-\rho t}[-C(e(t))-p(t) x(t)-S(v(t))]+\lambda(t)\left[e^{0}(t)+x(t)-\hat{e}(t)\right]
$$

is the Hamiltonian. ${ }^{11}$ Any solution to our problem, must satisfy the following conditions: ${ }^{12}$

$$
\begin{aligned}
-e^{-\rho t} C^{\prime}-e^{-\rho t} S^{\prime}+\mu & \leq 0, \quad e \geq 0, \quad e\left(-e^{-\rho t} C^{\prime}-e^{-\rho t} S^{\prime}+\mu\right)=0, \\
e^{-\rho t} S^{\prime}-\lambda-\mu & \leq 0, \quad \hat{e} \geq 0, \quad \hat{e}\left(e^{-\rho t} S^{\prime}-\lambda-\mu\right)=0, \\
\dot{B} & =e^{0}+x-\hat{e}, \\
\dot{\lambda} & =0, \\
e-\hat{e} \geq 0, \quad \mu \geq 0, \quad(e-\hat{e}) \mu=0, & \\
-e^{-\rho t} p+\lambda & =0 .
\end{aligned}
$$

We now provide a short economic interpretation for conditions (4)-(9). Note first that by equation (7), $\lambda$ or the marginal value of banked permits, is a positive constant with respect to time. ${ }^{13}$ The marginal value of banked permits can be interpreted as the firm's internal value of permits. The following proposition characterizes the evolution of the marginal abatement costs:

Proposition 1. Suppose the firm reports positive emissions, that is $\hat{e}>0$. Then $\lambda=$ $-e^{-\rho t} C^{\prime}$ and the marginal abatement costs increase at the rate of interest.

\footnotetext{
${ }^{11}$ We drop subscript $i$ and the time argument $t$.

${ }^{12}$ See Appendix A.2 for the more detailed necessary conditions. For a set of necessary conditions, see Seierstad and Sydsæter (1987) Theorem 2 on pages 85-86 and the discussion on page 270.

${ }^{13}$ From the assumptions about function $C$ and from conditions (4) and (5), it follows that $0<$ $-e^{-\rho t} C^{\prime} \leq e^{-\rho t} S^{\prime}-\mu \leq \lambda$.
} 
Proof. See Appendix A.1.

Studies in the literature on the evolution of emissions thus far implicitly assume full compliance (Rubin 1996, Kling and Rubin 1997). Next we calculate the time derivatives of emissions and reported emissions for the case where the firm chooses to be non-compliant with positive reported emissions. ${ }^{14}$ We study the time paths more generally in section 4. The fact that the marginal abatement costs increase at the rate of interest in this particular case turns out to have important implications for the time path of violations. When a firm reports positive emissions and is non-compliant, $\mu=0$ and equations (4) and (5) can be expressed as

$$
\begin{array}{r}
-e^{-\rho t} C^{\prime}-e^{-\rho t} S^{\prime}=0 \\
e^{-\rho t} S^{\prime}-\lambda=0 .
\end{array}
$$

Using equations (10) and (11), and assuming that $e$ and $\hat{e}$ are differentiable functions of time, we can study the time paths of emissions, reported emissions and violations in this particular case. Rewriting equations (10) and (11) as $-C^{\prime}=S^{\prime}=e^{\rho t} \lambda$, and differentiating with respect to time, we obtain $-C^{\prime \prime} \dot{e}=S^{\prime \prime} \dot{v}=\rho e^{\rho t} \lambda$. These and equation $\hat{e}=e-v$ imply

$$
\dot{e}=\frac{\rho C^{\prime}}{C^{\prime \prime}}, \quad \dot{v}=\frac{\rho S^{\prime}}{S^{\prime \prime}}, \quad \dot{\hat{e}}=\frac{\rho C^{\prime}}{C^{\prime \prime}}-\frac{\rho S^{\prime}}{S^{\prime \prime}}
$$

Hence both actual and reported emissions decrease in time. Even though emissions de-

\footnotetext{
${ }^{14}$ For some examples of emissions trading systems with both full compliance and partial compliance, see Stranlund (2007) and references there.
} 
crease over time, the decrease in the reported emissions is greater thus leading to violations that increase over time.

\section{Searching for full compliance in a dynamic framework}

We next focus on the necessary and sufficient conditions for the firm to be compliant to characterize the time paths of emissions and reported emissions from a more general perspective. In particular, we derive a lower bound for the discounted marginal expected penalty at zero violation, $e^{-\rho t} S^{\prime}(0)$, to yield full compliance. The literature shows that in a static world, inequality $S^{\prime}(0) \geq p$ is equivalent with the firm being compliant. ${ }^{15}$

Before moving on, we note that the optimal actual emissions and reported emissions are continuous functions of time. ${ }^{16}$ We are interested only in the case, in which the actual emissions are initially strictly positive. Since actual emissions are continuous, they are strictly positive during some interval $\left[0, t^{+}\right)$. We are interested in characterizing the condition for compliance in this time interval.

Proposition 2. Let $e(0)>0$. The statement that the firm is compliant for all $t \in\left[0, t^{+}\right)$ is equivalent to the inequality $e^{-\rho t} S^{\prime}(0) \geq \lambda$ for all $t \in\left[0, t^{+}\right)$.

Proof. See Appendix A.3.

\footnotetext{
${ }^{15}$ This may be found in Malik (1990) and in Stranlund and Dhanda (1999).

${ }^{16}$ This follows from Seierstad and Sydsæter (1987), page 86, Note 2. According to this note, the optimal control is continuous when the control set is convex and the Hamiltonian is strictly concave with respect to the controls. For the problem at hand, these conditions are satisfied for controls $e$ and $\hat{e}$, but not for $x$.
} 
This proposition states that a firm with strictly positive actual emissions is compliant if and only if the inequality $e^{-\rho t} S^{\prime}(0) \geq \lambda$ holds. Thus, the firm complies when the discounted marginal expected penalty at a zero violation level or the marginal expected cost of non-compliance is greater than or equal to the firm's internal value of permits or the marginal benefit of non-compliance. ${ }^{17}$ Proposition 2 can be used to characterize weak enforcement policy: when $e^{-\rho t} S^{\prime}(0)<\lambda$, the firm non-complies and the enforcement policy is weak.

Two observations immediately follow. First, the function on the left side, $t \mapsto e^{-\rho t} S^{\prime}(0)$, is strictly decreasing and reaches a unique maximum at $t=0$. Therefore, this inequality rules out cases for which the firm is non-compliant at $t_{1}$ but compliant at $t_{2}>t_{1}$.

Second, for a sufficiently distant terminal time $T$ (and sufficiently large $t^{+}$), there exists a value $t=\hat{t}$ such that $e^{-\rho \hat{t}} S^{\prime}(0)=\lambda$. In such a case the firm becomes non-compliant for $t>\hat{t}$. The reason for this is discounting: the discounted marginal cost of non-compliance has decreased enough compared to the marginal benefit of non-compliance to make it beneficial for the firm to under-report its emissions. These results show that even though the firm is compliant during some interval beginning from the first period, it may begin to be non-compliant at a later date. Therefore, some given penalty scheme may appear to work well enough initially, but may in fact turn out to be a poor choice later on. ${ }^{18}$

\footnotetext{
${ }^{17}$ An immediate corollary for this result is a sufficient condition for compliance: Let $e \geq 0$; if $e^{-\rho t} S^{\prime}(0) \geq$ $\lambda$, the firm is compliant.

${ }^{18}$ This result may change in a model, where only banking of permits is allowed. For a brief analysis of this, see Appendix A.4.
} 
We can use this proposition to conclude that multiple properties of the enforcement schemes from the static world carry over to the dynamic setting. The marginal expected penalty at zero violation should be at least equal to the permit price to induce full compliance as in the static models. This follows from the condition that the marginal value of banked permits $\lambda$ equals the discounted permit price, which implies that the inequality $e^{-\rho t} S^{\prime}(0) \geq \lambda$ is equivalent to $S^{\prime}(0) \geq p$. Therefore, the same enforcement scheme that leads to full compliance in the static case also leads to full compliance in the dynamic case in which firms can freely bank and borrow permits. This finding confirms the same result found by Stranlund et al. (2005) in discrete time with the objective probability of auditing. Another way to understand that a non-compliant firm cannot become compliant at a later date is that Hotelling's rule holds for the permit price. If a firm begins to non-comply at time $t_{1}$, inequality $S^{\prime}(0)<p\left(t_{1}\right)$ must hold. Because the permit price rises, inequalities $S^{\prime}(0)<p\left(t_{1}\right)<p\left(t_{2}\right)$ hold for $t_{1}<t_{2}$, and the firm will remain non-compliant.

\section{The time paths of emissions, reported emissions and violations.}

In this section, we characterize the optimal solution assuming that $e(0)>0$ and the expected penalty is such that the firm is compliant initially, but not necessarily afterwards. We also assume that inequality $e^{-\rho t} S^{\prime}(0)>\lambda$ holds at initial time $t=0$. This implies that the firm is compliant at time 0 . Equation $\lambda=-e^{-\rho t} C^{\prime}$ holds, so that the actual (and 
reported) emissions at a time slightly greater than zero are therefore given by

$$
e(t)=\left(-C^{\prime}\right)^{-1}\left(e^{\rho t}\left[-C^{\prime}(e(0))\right]\right)
$$

where $\left(-C^{\prime}\right)^{-1}$ is the inverse of $-C^{\prime}$ (see Appendix A.5). Since $-C^{\prime \prime}<0,-C^{\prime}$ is strictly decreasing in $e$. The basic properties of invertible functions imply that the inverse of $-C^{\prime}$, that is $\left(-C^{\prime}\right)^{-1}$, is also strictly decreasing. According to equation (12), emissions are therefore decreasing in time, when the firm is compliant. We are mostly interested in the case in which the firm becomes non-compliant, but note that time path $e(t)$ may hit zero and remain at zero until the end $T$. In such a case, the firm is compliant throughout the planning interval.

Turning to possible non-compliance, let $\hat{t}$ be the time instant that solves the equation $e^{-\rho t} S^{\prime}(0)=\lambda$. For $t>\hat{t}$, the firm is non-compliant. Since the controls are continuous in time, $\hat{e}(t)$ is positive at least for some interval after $\hat{t}$. During this interval, actual and reported emissions in addition to violations are given by

$$
\begin{gathered}
e(t)=\left(-C^{\prime}\right)^{-1}\left(e^{\rho(t-\hat{t})}\left[-C^{\prime}(e(\hat{t}))\right]\right), \\
\hat{e}(t)=\left(-C^{\prime}\right)^{-1}\left(e^{\rho(t-\hat{t})}\left[-C^{\prime}(e(\hat{t}))\right]\right)-\left(S^{\prime}\right)^{-1}\left(e^{\rho(t-\hat{t})}\left[S^{\prime}(v(\hat{t}))\right]\right),
\end{gathered}
$$

and

$$
v(t)=\left(S^{\prime}\right)^{-1}\left(e^{\rho(t-\hat{t})} S^{\prime}(v(\hat{t}))\right)
$$

where $\left(-C^{\prime}\right)^{-1}$ and $\left(S^{\prime}\right)^{-1}$ are the inverses of $-C^{\prime}$ and $S^{\prime}$ (see Appendix A.6). Note that in equations (14) and (15), $v(\hat{t})=0$. Emissions are according to (13) strictly decreasing 
in $t$, which is what was previously shown in subsection 2.2. Furthermore, function $S^{\prime}$ is strictly increasing, which implies that the reported emissions are also strictly decreasing in $t$ and that the violation is strictly increasing in $t$.

We summarize the results thus far in the following proposition.

\section{Proposition 3.}

(1) When the firm is compliant with positive actual emissions, actual emissions are strictly decreasing in time.

(2) When the firm is non-compliant and reported emissions are positive, actual emissions and reported emissions are strictly decreasing in time, and violation is strictly increasing in time.

When the reported emissions are positive, the marginal abatement cost equals the permit price. The permit price increases at the rate of interest, which implies that abatement increases (or emissions decrease) over time. Furthermore, when the firm is non-compliant with positive reported emissions, the marginal expected penalty equals the permit price, which thus implies that the violation level increases over time. This result is intuitive, because the permit price is the marginal benefit of non-compliance, and along the optimal path the marginal benefit equals the marginal expected cost. Therefore, the firm finds it optimal to increase violation. 
We next argue that given a sufficiently large terminal time the reported emissions become zero at some time instant $t^{0}$.

Proposition 4. Suppose the firm becomes non-compliant at some time $\hat{t}$. Then, for a sufficiently large $T$, there exists a value $t=t^{0}$ such that $\hat{e}\left(t^{0}\right)=0$.

Proof. See Appendix A.7.

Proposition 4 shows that for a large $T$, reported emissions at some point become zero. The violation level increases over time, but at time $t^{0}$ this increase ceases. ${ }^{19}$ We next argue that after $t^{0}$, the actual emissions remain constant.

Proposition 5. Suppose the firm becomes non-compliant at some time $\hat{t}$. Then, the actual emissions are constant when $t>t^{0}$.

Proof. See Appendix A.8.

Figure 1 illustrates the propositions.

\footnotetext{
${ }^{19}$ One may object to this result, since zero reported emissions may be seen as a signal of non-compliance, which may trigger an instant audit. In this model, actual emissions can also be zero, thus implying that zero reported emissions do not imply non-compliance. Besides, a literal interpretation of Proposition 4 (or models in general) may prove rather useless, for example, due to modeling uncertainties. An alternative to the literal interpretation is that the reported emissions became increasingly smaller over time.
} 


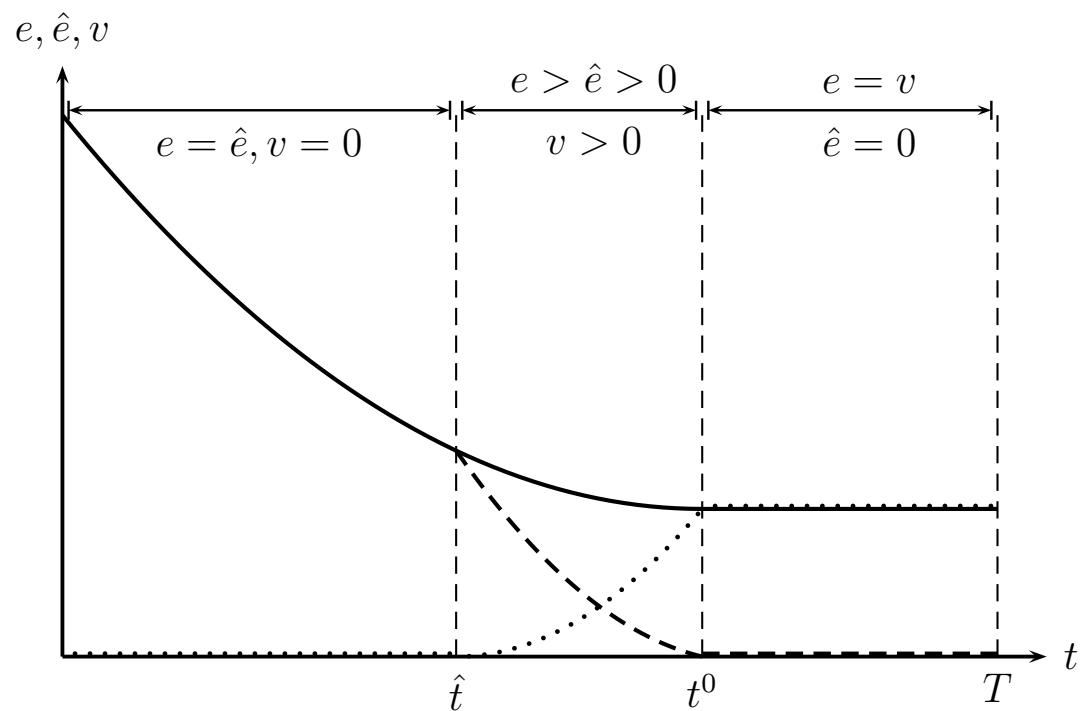

Figure 1: Time paths of $e, \hat{e}$ and $v$ for sufficiently large $T$. The solid line is the path of actual emissions, and the dashed line is the path of reported emissions. The dotted line denotes violations.

What is the intuition for constant emissions after $t^{0}$ ? Reported emissions are zero, thus the level of violation is determined solely by the level of actual emissions. At the optimum, the marginal benefit of emissions must therefore be just equal to the marginal cost of non-compliance. More exactly, by condition (4) and because $\hat{e}(t) \equiv 0$ after $t^{0}$, the optimal actual emissions satisfy equation $-C^{\prime}(e(t))=S^{\prime}(e(t))$. That is, after $t^{0}$, the marginal abatement cost equals the marginal expected penalty, and the violation level is determined solely by the level of actual emissions.

Figure 2 offers further illustration for Proposition 5. 

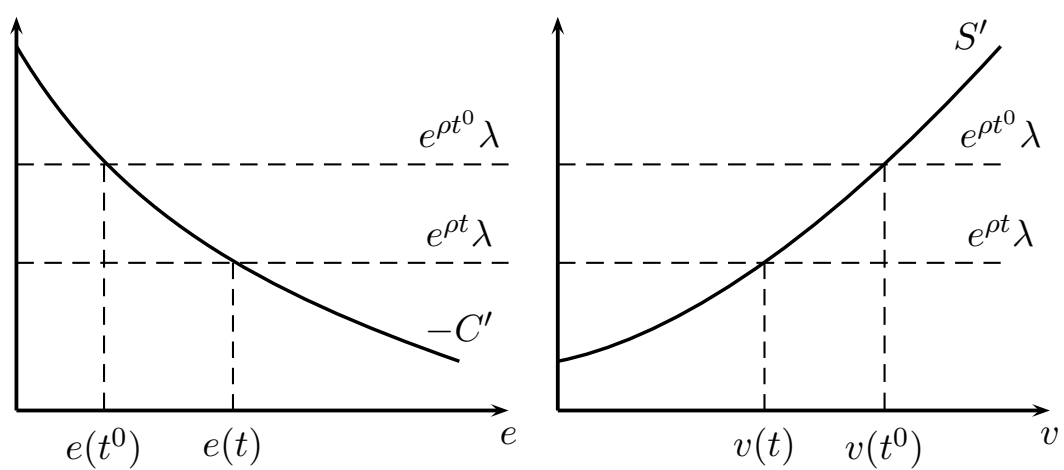

Figure 2: An illustration of the constant actual emission level. As the value of $e^{\rho t} \lambda$ grows to $e^{\rho t^{0}} \lambda$, the marginal expected penalty $S^{\prime}$ and the marginal abatement cost $-C^{\prime}$ obtain the same value, and the actual emissions and violation level stabilize to $e\left(t^{0}\right)$.

Note that $-C^{\prime}=e^{\rho t} \lambda$ and $S^{\prime}=e^{\rho t} \lambda$ for all the time instants before $t^{0}$. Because the right-sides of these equations increase in time, the optimal actual emissions must decrease and optimal violation must increase in time. When the marginal abatement costs and the marginal expected penalty become equal to $e^{\rho t^{0}} \lambda$, the actual emissions and violations become constant. Note that as the marginal expected penalty or the marginal abatement cost becomes flatter, the actual emissions will stabilize at a higher level. The figure can also be used to characterize a rough sufficient condition for compliance: if the marginal expected penalty is always greater than the marginal abatement cost (that is, if $\left.S^{\prime}(0)>C^{\prime}(0)\right)$, the firm is always compliant. This is intuitive, since the condition says that the marginal expected cost of non-compliance is higher than the marginal benefit of non-compliance.

To recap, when actual emissions are initially nonzero, there are essentially four possibil- 
ities for the optimal time paths of actual and reported emissions in addition to violations. The first possibility is that the firm is compliant throughout the planning interval. This is essentially the case that Rubin (1996) studied. ${ }^{20}$ Rubin does not consider the other possibilities. When the terminal time is not too long, that is when the terminal time comes after $\hat{t}$ but before $t^{0}$, the violation time path begins increasing until the terminal time is reached. The most surprising results occur when the terminal time exceeds $t^{0}$. In such a case, the reported emissions become zero at some point in time, and actual emissions and violations stabilize at a constant level. It is therefore possible, that for a sufficiently large terminal time, every firm will begin to report zero emissions. Even though total reported emissions are zero, the regulator cannot in practice infer an overall level of non-compliance without monitoring, because there are other sources of pollution in addition to the firms. This holds in particular for $\mathrm{CO}_{2}$ and for water pollutants.

These results allow us to analyze some other impacts of banking during the planning period. Let $E^{0}(t)$ denote the total allocation of permits at time $t$. The total allocation over the planning period must be equal to the total number of reported emissions:

$$
\int_{0}^{T} E^{0}(t) \mathrm{d} t=\sum_{i=1}^{k}\left(\int_{0}^{\hat{t}_{i}} e_{i}(t) \mathrm{d} t+\int_{\hat{t}_{i}}^{T} \hat{e}_{i}(t) \mathrm{d} t\right)+\sum_{i=k+1}^{n} \int_{0}^{T} e_{i}(t) \mathrm{d} t
$$

where $k$ is the number of firms that begin to non-comply. The existence of time periods, during which the firms begin to non-comply, depends on the firms' characteristics (on

\footnotetext{
${ }^{20}$ The one possibility missing from the text, which was discussed after equation (12), is where the firm is always compliant and actual emissions reach zero, where they remain until the terminal time.
} 
the subjective auditing probability) and on the length of the planning interval. It may therefore well be that all the firms comply. In such a case, condition (16) collapses to that described by Rubin (1996), where the total allocation over the time interval equals the total actual emissions. Otherwise, when $k>0$, a gap results between the total allocation and the actual emissions of the firms. This gap grows with terminal time $T$. There are two (main) reasons for this. First, a firm that begins to non-comply at some point increases its violations over time. ${ }^{21}$ Second, the number of non-compliant firms may increase over time.

Non-compliance also affects permit banking. The market clearing condition, $\sum_{i=1}^{n} x_{i}(t)=$ 0 for all $t$, allows us to deduce that the aggregate permits banked at time $t<T$, denoted with $B_{\Sigma}(t)$, is given by

$$
\int_{0}^{t} \dot{B}_{\Sigma}(s) \mathrm{d} s=\int_{0}^{t} \sum_{i=1}^{n}\left(e_{i}^{0}(s)-\hat{e}_{i}(s)\right) \mathrm{d} s
$$

Let function $B_{\Sigma}^{n c}(t)$ denote total permit banking at time $t$, when at least one firm has begun to non-comply before time $t$, and let function $B_{\Sigma}^{c}(t)$ denote total banking when every firm complies at time $t$. We have that $B_{\Sigma}^{n c}(t)>B_{\Sigma}^{c}(t)$, which means that the total banking is greater with non-compliant firms than with compliant firms. Also, the difference between $B_{\Sigma}^{n c}(t)$ and $B_{\Sigma}^{c}(t)$ grows over time.

\footnotetext{
${ }^{21}$ By propositions 4 and 5 this increase may cease at some point $t_{i}^{0}$.
} 


\section{Discussion}

We briefly discuss the relationship of the current study to the previous research on noncompliance and permit banking, the practical relevance of the model and its policy implications in this section. Stranlund et al. (2005) analyzed in their model the enforcement of emissions trading schemes with banking of permits, and they found that making the penalty for under-reported emissions dependent on the going permit price can be used to induce full-compliance, and that increasing the penalty can save monitoring costs. In this paper we have extended the literature by characterizing the consequences of weak enforcement policy on the time paths of emissions, reported emissions and violation level (Propositions 3-5).

It is well recognized that permit banking is a key feature for successful trading programs, which produces cost-savings (Schmalensee and Stavins 2015). The current model allows for banking and borrowing and as such it is best linked to three emissions trading programs, the RGGI, the EU ETS and the Quebéc Cap and Trade System. In the RGGI program unlimited borrowing is allowed during the three year compliance period whereas in the EU ETS the firms are allowed to freely borrow the permits from the next years allocation (Holland and Moore 2013). The rules in the Quebéc Cap and Trade System are similar to those of RGGI program. These programs allow the banking and borrowing of permits, and therefore, when the terminal time is $T=3$ the model is related to the 
RGGI and to the Quebéc Cap and Trade System, and when the terminal time $T=2$ to the EU ETS. Whether or not the length of these planning intervals is sufficient to allow for the outcomes reported in this study is an empirical question.

We now turn to the policy implications. First, some issued penalty scheme may be suboptimal, in that it might fail to induce full compliance throughout the planning period, even though the evidence at hand shows a high level of past compliance. Second, in the enforcement and monitoring literature, sanctioning costs are sometimes modeled as an increasing function of the violation (Stranlund 2007, Stranlund and Moffitt 2014). Results show that with permit banking, the violations may begin to increase eventually. This implies that sanctioning costs begin increasing at the same time. Banking permits could therefore incur additional costs on society. Moroever, since non-compliant firms raise their violation level over time, a tighter enforcement may be necessary, which also incurs higher costs on society. In addition, the regulator should be clear about the enforcement policy. In this way the firm's subjective auditing probability may be closer to the actual auditing probability.

The benefit of permit banking is that it may generate intertemporal cost savings. The results here show that permit banking may raise the costs on society in the form of greater enforcement and sanctioning costs and higher actual emissions. Actual total emissions are higher with non-compliance than with compliance. Therefore, one should take into account these effects of non-compliance when considering the banking and borrowing of 
permits.

\section{Conclusions}

This study analyzes the effects of non-compliance in emissions trading when firms are allowed to bank and borrow permits. The main contributions of this study are the characterization of the condition for compliance and the analysis of the time paths of emissions and violations. The condition involves the marginal expected cost of non-compliance, which may be unknown to the regulator, since the probability of an audit can be subjective. This compromises the ability of the regulation to achieve full compliance. We found two interesting time instants: one at which the firm begins to non-comply, and another at which reported emissions reach zero and actual emissions become constant.

The current model and analysis can be extended to many directions. The probability of an audit in the current model depends on the absolute level of violation, which implies that this probability is the same as when reported emissions are zero (and actual emissions 500) and when reported emissions are 1500 (and actual emissions 2000). It may be expected that zero reported emissions yield a higher probability of auditing compared to positive reported emissions even if the violation size is the same. Therefore, it would be interesting to generalize the audit probability function to allow the probability to depend on the size of relative violation, as described in the studies by Hatcher (2005) and by Lappi (2016).

Moreover, both banking and borrowing of permits are allowed in the current model. 
However, there are multiple emissions trading programs that allow only banking. ${ }^{22}$ Therefore it would be worthwhile to consider adding a banking state constraint $(B \geq 0)$ to a non-compliance model and to analyze the optimal controls, although this kind of pure state constraint may raise additional technical difficulties.

The current model is very stylized, and therefore the most notable extension would be to analyze the emission choice decision and the potential for non-compliance in a more detailed model covering the rules currently applied in different emissions trading schemes. Additionally, the permit price should be made endogenous. The static analysis of Lappi (2016) suggests that given the expected penalties there is an equilibrium configuration of compliant and non-compliant firms (with their emission, reported emission and violation level choices) and an equilibrium permit price, that is lower than the price with full-compliance. Endogenous price would allow further analysis on the effects of weak enforcement policy.

\footnotetext{
${ }^{22}$ One example is the U.S. Acid Rain Program. For other examples see Table 1 in Holland and Moore (2013).
} 


\section{Appendices}

\section{A.1}

Proof of Proposition 1.

For $\hat{e}>0$, (4) and (5) imply that equation $-e^{-\rho t} C^{\prime}(e)=\lambda$ holds. This implies the result.

\section{A.2}

Necessary conditions are:

$$
\begin{aligned}
L_{e} & =-e^{-\rho t} C^{\prime}-e^{-\rho t} S^{\prime}+\mu+\gamma_{1}=0, \quad \gamma_{1} \geq 0, \quad e \geq 0, \quad \gamma_{1} e=0, \\
L_{\hat{e}} & =e^{-\rho t} S^{\prime}-\lambda-\mu+\gamma_{2}=0, \quad \gamma_{2} \geq 0, \quad \hat{e} \geq 0, \quad \gamma_{2} \hat{e}=0, \\
L_{x} & =-e^{-\rho t} p+\lambda=0, \\
\dot{B} & =e^{0}+x-\hat{e}, \\
\dot{\lambda} & =-L_{B}=0, \\
e-\hat{e} & \geq 0, \quad \mu \geq 0, \quad(e-\hat{e}) \mu=0 .
\end{aligned}
$$

\section{A.3}

Proof of Proposition 2. $\Rightarrow$ : Assume that the firm is compliant, that is, assume that $v=0$. Then $\hat{e}>0$ and by condition (8), $\mu \geq 0$. Therefore, by condition (5), the inequality $e^{-\rho t} S^{\prime}(0)-\lambda \geq 0$ holds, that is, $e^{-\rho t} S^{\prime}(0) \geq \lambda$. $\Leftarrow$ : Assume that $e^{-\rho t} S^{\prime}(0) \geq \lambda$ for all $t \in\left[0, t^{+}\right)$, but that the firm is non-compliant, that is, assume that $v>0$, at some 
$\bar{t} \in\left[0, t^{+}\right)$. Then by condition (8), $\mu=0$ at time $\bar{t}$, so that $e^{-\rho \bar{t}} S^{\prime}(v) \leq \lambda$. Then

$$
e^{-\rho \bar{t}} S^{\prime}(v) \leq \lambda \leq e^{-\rho \bar{t}} S^{\prime}(0)
$$

From assumption $S^{\prime \prime}>0$, it follows that $v \leq 0$ at time $\bar{t}$, which contradicts the assumption that the firm is non-compliant at time $\bar{t}$. Therefore, the firm is compliant.

\section{A.4}

When only banking of permits is allowed

Consider the case, where only banking of permits is allowed. This means that the optimization problem $(\mathrm{P})$ now includes an additional constraint $B \geq 0$. This is a pure state constraint and therefore we use the informal theorem 4 from Hartl, Sethi and Vickson (1995) to develop the necessary conditions for optimality. Let $\nu$ be a piecewise continuous multiplier for the state constraint, and suppose $B$ has finitely many junction times $\tau_{1}, \ldots, \tau_{m}$. Then the following conditions are necessary for optimality:

$$
\begin{gathered}
\text { conditions }(5),(6),(7),(9),(10), \\
\dot{\lambda}=-\nu, \\
\nu \geq 0, \nu B=0, \\
\lambda\left(\tau^{+}\right)-\lambda\left(\tau^{-}\right)=-\eta(\tau), \\
\eta(\tau) \geq 0, \eta(\tau) B(\tau)=0,
\end{gathered}
$$

where $\eta(\tau)$ are numbers for every point of discontinuity of $\lambda$. The discontinuities of $\lambda$ 
can happen at time instants on the boundary interval or at contact times. Condition $e^{-\rho t} S^{\prime}(0) \geq \lambda$ is equivalent with the firm being compliant at time $t$ also in this model. It follows from (A.24)-(A.27) that, when $B>0$, the firm's compliance behavior is characterized by the same properties as in the model, where borrowing is allowed. This is because the function $\lambda$ is constant for $B>0$.

However, in the cases where the state constraint is binding, the marginal value of banked permits is no longer constant and possibly not even continuous. In fact, from (A.24)-(A.27), we obtain that $\lambda$ is a decreasing function. This implies that both sides of the inequality $e^{-\rho t} S^{\prime}(0) \geq \lambda$ are decreasing in time. Therefore a non-compliant firm can, in principle, turn compliant at some instant of time, when only permit banking is allowed - a result that was impossible, when borrowing was allowed.

\section{A.5}

For all $t$ slightly greater than $0, v \equiv 0$. It therefore follows from the necessary conditions that $-e^{-\rho t} C^{\prime}(e)=\lambda$. Since $\dot{\lambda}=0$, we obtain equation:

$$
\rho e^{-\rho t} C^{\prime}(e)+e^{-\rho t}\left[-C^{\prime}(e)\right]=0 .
$$

Integrating this gives

$$
-C^{\prime}(e(t))=e^{\rho t}\left[-C^{\prime}(e(0))\right]
$$

which implies that $e(t)=\left(-C^{\prime}\right)^{-1}\left(e^{\rho t}\left[-C^{\prime}(e(0))\right]\right)$. 


\section{A. 6}

Let $e>0, \hat{e}>0$ and $e-\hat{e}>0$ for $t$ slightly greater than $\hat{t}$. Then, by the necessary conditions, $\mu=0,-e^{-\rho t} C^{\prime}(e)-e^{-\rho t} S^{\prime}(v)=0, e^{-\rho t} S^{\prime}(v)-\lambda=0$, and $\dot{\lambda}=0$. Therefore

$$
-e^{-\rho t} C^{\prime}(e)=e^{-\rho t} S^{\prime}(v)=\lambda .
$$

Since $\dot{\lambda}=0$, we obtain equations:

$$
\rho e^{-\rho t} C^{\prime}(e)+e^{-\rho t}\left[-\dot{C}^{\prime}(e)\right]=0,
$$

and

$$
-\rho e^{-\rho t} S^{\prime}(v)+e^{-\rho t}\left[S^{\prime}(v)\right]=0 .
$$

Integrating these results in

$$
-C^{\prime}(e(t))=e^{\rho(t-\hat{t})}\left[-C^{\prime}(e(\hat{t}))\right]
$$

and

$$
S^{\prime}(v(t))=e^{\rho(t-\hat{t})} S^{\prime}(v(\hat{t}))
$$

Solving (A.33) for $e$ :

$$
e(t)=\left(-C^{\prime}\right)^{-1}\left(e^{\rho(t-\hat{t})}\left[-C^{\prime}(e(\hat{t}))\right]\right) .
$$

Solving (A.34) for $v$ :

$$
v(t)=\left(S^{\prime}\right)^{-1}\left(e^{\rho(t-\hat{t})} S^{\prime}(v(\hat{t}))\right) .
$$


Since $v=e-\hat{e}$, we finally obtain

$$
\hat{e}=e-v=\left(-C^{\prime}\right)^{-1}\left(e^{\rho(t-\hat{t})}\left[-C^{\prime}(e(\hat{t}))\right]\right)-\left(S^{\prime}\right)^{-1}\left(e^{\rho(t-\hat{t})}\left[S^{\prime}(e(\hat{t})-\hat{e}(\hat{t}))\right]\right) .
$$

\section{A.7}

Proof of Proposition 4. We apply the intermediate value theorem to function $Z:[\hat{t}, T] \rightarrow \mathbb{R}$ defined with

$$
Z(t)=\left(-C^{\prime}\right)^{-1}\left(e^{\rho(t-\hat{t})}\left[-C^{\prime}(e(\hat{t}))\right]\right)-\left(S^{\prime}\right)^{-1}\left(e^{\rho(t-\hat{t})} S^{\prime}(0)\right)
$$

Note that $Z(\hat{t})=e(\hat{t})>0$. Next we show that there exists a $t^{-} \in[\hat{t}, T]$ such that $Z\left(t^{-}\right)<0$.

Since actual emissions are decreasing in time, the violation can be at most $e(0)$. The marginal expected penalty function $S^{\prime}$ is strictly increasing and maps $[0, e(0))$ to $[m, M)$. Since $\sup _{w \in[m, M)}\left(S^{\prime}\right)^{-1}(w)=e(0)$, for each $\epsilon>0$ there exists $x \in \operatorname{Im}\left(S^{\prime}\right)^{-1}$ such that $x>e(0)-\epsilon$. In particular, for $\epsilon=\frac{e(0)-e(\hat{t})}{2}$ there exists $x \in \operatorname{Im}\left(S^{\prime}\right)^{-1}$ such that $x>$ $e(0)-\frac{e(0)-e(\hat{t})}{2}$ and $x=\left(S^{\prime}\right)^{-1}(z)$, where $z=e^{\rho(t-\hat{t})} S^{\prime}(0)$ for some $t \in[\hat{t}, T]$. Denoting this time instant with $t^{-}$, gives us

$$
Z\left(t^{-}\right)<e(\hat{t})-\left(S^{\prime}\right)^{-1}\left(e^{\rho\left(t^{-}-\hat{t}\right)} S^{\prime}(0)\right)<e(\hat{t})-e(0)+\frac{e(0)-e(\hat{t})}{2}=\frac{e(\hat{t})-e(0)}{2}<0
$$

Because $Z$ is continuous, the intermediate value theorem states that a value $t^{0} \in[\hat{t}, T]$ exists such that $Z\left(t^{0}\right)=0$ or, equivalently, $\hat{e}\left(t^{0}\right)=0$. 


\section{A.8}

Proof of Proposition 5. Let $t>t^{0}$. We first show that the inequality

$$
e^{-\rho t} S^{\prime}(v(t))<\lambda
$$

holds. Assume on the contrary that $e^{-\rho t} S^{\prime}(v(t)) \geq \lambda$. At time $t^{0}, \hat{e}=0$, so $e^{-\rho t^{0}} S^{\prime}\left(v\left(t^{0}\right)\right)=$ $e^{-\rho t^{0}} S^{\prime}\left(e\left(t^{0}\right)\right)$. Condition (5) shows that $e^{-\rho t^{0}} S^{\prime}\left(e\left(t^{0}\right)\right) \leq \lambda$ since $\mu=0$. Therefore

$$
e^{-\rho t} S^{\prime}(v(t)) \geq e^{-\rho t^{0}} S^{\prime}\left(e\left(t^{0}\right)\right)
$$

Inequality

$$
S^{\prime}(v(t))>S^{\prime}\left(e\left(t^{0}\right)\right)
$$

must therefore hold, because $e^{-\rho t}<e^{-\rho t^{0}}$. Inequality (A.42) implies that $v(t)>e\left(t^{0}\right)$, so that $e(t)>e\left(t^{0}\right)$. But for all $t>t^{0}$, equality $-C^{\prime}(e(t))=S^{\prime}(v(t))$ holds. This and inequality (A.42) imply that $-C^{\prime}(e(t))>-C^{\prime}\left(e\left(t^{0}\right)\right)$. Thus $e(t)<e\left(t^{0}\right)$. We have therefore reached a contradiction, so inequality (A.40) holds.

Since $t>\hat{t}, \mu \equiv 0$. By condition (5), this and inequality (A.40) imply that $\hat{e}(t)=0$ for $t>t^{0}$. Then, by condition $(4),-e^{\rho t} C^{\prime}(e(t))-e^{\rho t} S^{\prime}(e(t))=0$. This is equivalent to $-C^{\prime}(e(t))-S^{\prime}(e(t))=0$, which implies that the actual emissions are constant.

\section{References}

[1] Arguedas C, Camacho E, Zofío JL (2010) Environmental policy instruments: technology adoption incentives with imperfect compliance. Environ Resource Econ 47:261- 
[2] Chevallier J (2012) Banking and borrowing in the EU-ETS: A review of economic modelling, current provisions and prospects for the future design. J Econ Surveys $26: 157-176$.

[3] Cronshaw MB, Kruse JB (1996) Regulated firms in pollution permit markets with banking. J Regul Econ 9:179-189

[4] European Commission, EU ETS Handbook. Available online from http://ec.europa.eu/clima/publications/docs/ets_handbook_en.pdf (retrieved on 2.2.2016)

[5] Van Egteren H, Weber M (1996) Marketable permits, market power and cheating. J Environ Econ Manage 30:161-173

[6] Hartl RF, Sethi SP, Vickson RG (1995) A Survey of the Maximum Principles for Optimal Control Problems with State Constraints. SIAM Review 37:181-218

[7] Hatcher A, (2005) Non-compliance and the quota price in an ITQ fishery. J Environ Econ Manage 49:427-436

[8] Hatcher A, (2012) Market power and compliance with output quotas. Resour and Energy Econ 34:255-269 
[9] Holland SP, Moore MR (2013) Market design in cap and trade programs: permit validity and compliance timing. J Environ Econ Manage 66:671-687

[10] Innes R (2003) Stochastic pollution, costly sanctions, and optimality of emission permit banking. J Environ Econ Manage 45:546-568

[11] Kling C, Rubin J (1997) Bankable permits for the control of environmental pollution. J Public Econ 64:101-115

[12] Lappi P, (2016) The welfare ranking of prices and quantities under noncompliance. Int Tax Public Finan 23:269-288

[13] Leard B, (2013) The welfare effects of allowance banking in emissions trading programs. Environ Resource Econ 55:175-197

[14] Macho-Stadler I, Pérez-Castrillo D, (2006) Optimal enforcement policy and firms' emissions and compliance with environmental taxes. J Environ Econ Manage 51:110131

[15] Malik AS, (1990) Markets for pollution control when firms are noncompliant. J Environ Econ Manage 18:97-106

[16] Malik AS (1992) Enforcement costs and the choice of policy instruments for controlling pollution. Econ Inquiry 30:714-721 
[17] Malik AS (2002) Further results on permit markets with market power and cheating. J Environ Econ Manage 44:371-390

[18] Montero JP, (2002) Prices versus quantities with incomplete enforcement. J Public Econ 85:435-454

[19] Okat D. (2016) Deterring Fraud by Looking Away. RAND J Econ. In press.

[20] Quebéc Government, Publications. Regulation respecting a cap-and-trade system for greenhouse gas emission allowances. Available online from http://www2 . publicationsduquebec.gouv.qc.ca/dynamicSearch/telecharge. php?type=3\&file=/Q_2/Q2R46_1_A.HTM (retrieved on 3.5.2016)

[21] Rubin JD (1996) A model of intertemporal emissions trading, banking and borrowing. J Environ Econ Manage 31:269-286.

[22] Sandmo A, (2002) Efficient environmental policy with imperfect compliance. Environ Resource Econ 23:85-103

[23] Schennach SM (2000) The economics of pollution permit banking in the context of Title IV of the 1990 Clean Air Act Amendments. J Environ Econ Manage 40:189-210

[24] Schmalensee R, Stavins RN (2015) Lessons Learned from Three Decades of Experience with Cap-and-Trade. Resources for the Future. Discussion paper. 
[25] Seierstad A, Sydsæter K (1987) Optimal Control Theory with Economic Applications, first ed. Elsevier Science Publishers, Amsterdam.

[26] Stranlund JK, Chávez CA, Villena MG (2009) The optimal pricing of pollution when enforcement is costly. J Environ Econ Manage 58:183-191

[27] Stranlund JK (2007) The regulatory choice of noncompliance in emissions trading programs. Environ Resource Econ 38:99-117

[28] Stranlund JK, Costello C, Chávez CA (2005) Enforcing emissions trading when emissions permits are bankable. J Regul Econ 28:181-204

[29] Stranlund JK, Dhanda KK (1999) Endogenous monitoring and enforcement of a transferable emissions permit system. J Environ Econ Manage 38:267-282

[30] Stranlund JK, Moffitt JL, (2014) Enforcement and price controls in emissions trading. J Environ Econ Manage 67:20-38 